\title{
INTRODUCTORY STATEMENT
}

I am pleased to be associated with this initiative because it deals with a subject of great importance to all of us as Canadians. Bill Stinson has stressed that the business community must get involved. He has pointed to the critical linkage between economic strength and political stability. I would add another perspective. Reform of the constitution and deciding on how to govern ourselves is too important to be left only to politicians and officials. It is the responsibility of all citizens to understand what the issues are and what is at stake. This requires an open mind and access to carefully developed points of view.

Professor Watts and his team who have been working on this project for some six months, were asked at the outset to examine a variety of options for shaping Canada's constitutional future. In the presentations in this volume a number of options are discussed and diverse perspectives are offered on a wide range of issues that cover politics, economics, social dimensions, and culture. The objective of the symposium was not to reach any definitive conclusions but rather to inform and to stimulate thought and debate.

In the coming months, whether we like it or not, the debate about Canada's political future will intensify. It is critical that the debate be constructive and that it lead to change that will be welcomed by the vast majority of Canadians. Canada is a remarkable country. It has a record of success with few parallels in the world. But it is apparent now that some changes to how we govern ourselves will be necessary to ensure that we enter the twenty-first century with the political, economic, and social cohesion that befits a leading industrial power.

I am delighted that so many members of the Business Council demonstrated their interest in this vital subject by being at the symposium on 16 January 1991, and that so many of the special guests we invited accepted our invitation. The presentations throughout the day were stimulating and rewarding.

Guy Saint-Pierre

Co-chairman, Symposium on Canada's Constitutional Options 
